\title{
Provincial economic crisis concerns Newfoundland and Labrador doctors
}

$\mathrm{F}$ or Newfoundland and Labrador, the times have never been tougher, according to Dr. John Haggie, the province's minister of health and community services.

In a speech to the Primary Healthcare Forum, Haggie compared Newfoundland and Labrador's economy to that of a developing nation. "We're in a fiscal hole that's unparalleled in Canadian history in any jurisdiction," he said. "We're on a par with Puerto Rico and Venezuela where they turn the lights off for eight hours a day to try to make the books balance. That's how bad things are financially."

Things are not much better when it comes to the health of the population. According to Haggie, the province spends 29\% more per capita than any other comparable jurisdiction, but is not healthier for the additional \$1127 spent per person.

"We have some of the worst rates of population health outcomes and statistics in the country, the highest rates of chronic diseases. We've got the highest rates of obesity, inactivity and smoking," he says.

The Newfoundland and Labrador Medical Association is holding a conference later this fall that will focus exclusively on the need for a thorough, inclusive and independent review of health services in the province. It will pre-empt the supplemental budget due before year's end, which is expected to contain deep cuts to programs and services.

According to the province's auditor general, Canada's easternmost province recorded an unprecedented deficit of $\$ 986$ million in 2014/15. And it is not expected to be a onetime occurrence. Additional deficits, totalling $\$ 12.2$ billion, are forecast to 2021.

In his 74-page report, Auditor General Terry Paddon noted that Newfoundland and Labrador's deficit as a percentage of gross domestic product (one of the primary indicators used to gauge the health of the economy) for $2014 / 15$ was $2.9 \%$, more than twice

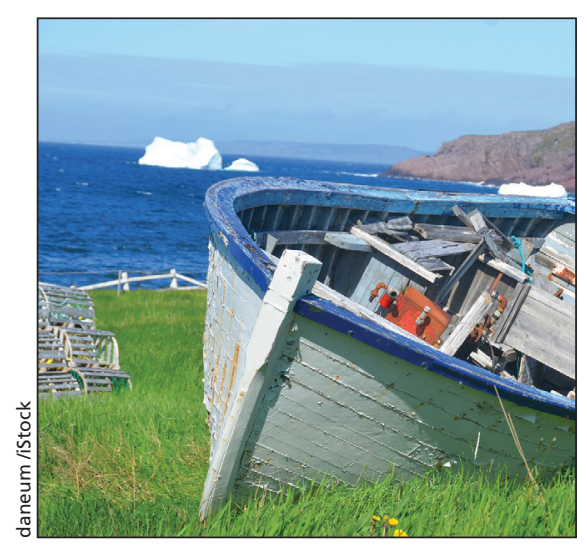

An unprecedented deficit in Newfoundland and Labrador has led to a call for a thorough assessment of health spending.

that of the next highest province. This percentage is only going to grow. In 2016/17, this number is expected to hit $6.5 \%$, roughly 3.5 times greater than the next highest province.

"Throughout the forecast period, the Province is facing deficits that, in relation to the size of the economy, will be up to 13 times higher than the average of all the other provinces, well beyond what would be considered reasonable and sustainable," Paddon wrote in his report.

He noted that $\$ 3$ billion of the $\$ 7.1$ billion of program expenses were attributed to the Department of Health and Community Services. Of every program expense dollar spent in Newfoundland and Labrador, $42 \%$ is spent on health care.

In an interview with reporters after his speech, Haggie warned residents to prepare for the worst. "What we're going to have to do and what we've tried to do within health is try to identify those areas where the return on expenditure has been minimal or zero and stop doing that."

The threat of deep cuts has the Newfoundland and Labrador Medical Association extremely concerned, says President-Elect Dr. Lynn Dwyer. "We realize that changes need to be made, but discussion needs to occur." donalee Moulton, Halifax, NS

CMAJ 2016. DOI:10.1503/cmaj.109-5335 